\title{
Right ventricular stroke work index by echocardiography in adult patients with pulmonary arterial hypertension
}

\author{
Raluca Jumatate ${ }^{1 *}$, Annika Ingvarsson', Gustav Jan Smith', Anders Roijer ${ }^{1}$, Ellen Ostenfeld ${ }^{2}$, Johan Waktare ${ }^{3}$, \\ Göran Rådegran ${ }^{1}$, Carl Meurling ${ }^{1}$ and Anna Werther Evaldsson ${ }^{1}$
}

\begin{abstract}
Background: In adult patients with pulmonary arterial hypertension (PAH), right ventricular (RV) failure may worsen rapidly, resulting in a poor prognosis. In this population, non-invasive assessment of RV function is challenging. RV stroke work index (RVSWI) measured by right heart catheterization (RHC) represents a promising index for RV function. The aim of the present study was to comprehensively evaluate non-invasive measures to calculate RVSWI derived by echocardiography (RVSWI $\mathrm{ECHO}_{\mathrm{O}}$ ) using $\mathrm{RHC}\left(\mathrm{RVSWI} \mathrm{RHC}_{\mathrm{R}}\right.$ ) as a reference in adult PAH patients.

Methods: Retrospectively, 54 consecutive treatment naïve patients with PAH ( $65 \pm 13$ years, 36 women) were ana-

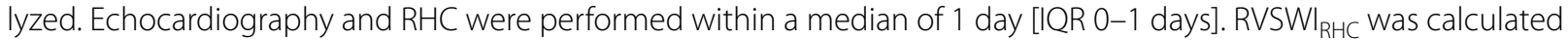
as: (mean pulmonary arterial pressure (mPAP) — mean right atrial pressure (mRAP)) x stroke volume index (SVI) ${ }_{\mathrm{RHC}}$. Four

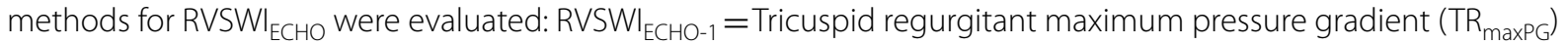
$\times S V I_{E C H O}, R V S W I_{E C H O-2}=\left(T_{R_{\text {maxPG }}-m R A P} \mathrm{ECHO}\right) \times S V I_{E C H O}, R V S W I_{E C H O-3}=T R$ mean gradient $\left(T_{\text {meanPG }}\right) \times S V I_{E C H O}$ and $\mathrm{RVSWI}_{\mathrm{ECHO}-4}=\left(\mathrm{TR}_{\text {meanPG}}-\mathrm{mRAP} \mathrm{ECHO}_{\mathrm{O}}\right) \times \mathrm{SVI}_{\mathrm{ECHO}}$. Estimation of mRAP $\mathrm{ECHO}_{\mathrm{O}}$ was derived from inferior vena cava diameter.

Results: RVSWI $\mathrm{RHC}_{\text {Was }} 1132 \pm 352 \mathrm{mmHg}^{*} \mathrm{~mL}^{*} \mathrm{~m}^{-2}$. In comparison with RVSWI $\mathrm{RHC}_{\mathrm{C}}$ in absolute values, RVSWI $\mathrm{ECHO}_{1}$ and RVSWI $\mathrm{ECHO}_{2}$ was significantly higher $(p<0.001)$, whereas RVSWI $\mathrm{ECHO}_{4}$ was lower $(p<0.001)$. No difference was shown for RVSWI $\mathrm{ECHO}_{3}(p=0.304)$. The strongest correlation, with RVSWI $\mathrm{RHC}_{\text {, was demonstrated for RVSWI }} \mathrm{ECHO}-2$

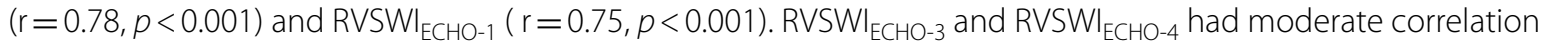
$\left(r=0.66\right.$ and $r=0.69, p<0.001$ for all). A good agreement (ICC) was demonstrated for RVSWI $\mathrm{ECHO}_{-3}(\mathrm{ICC}=0.80,95 \% \mathrm{Cl}$ 0.64-0.88, $p<0.001)$, a moderate for RVSWI $\mathrm{ECHO}_{4}(\mathrm{ICC}=0.73,95 \% \mathrm{Cl} 0.27-0.87, p<0.001)$ and RVSWI $\mathrm{ECHO}_{-2}(\mathrm{ICC}=0.55$, $95 \% \mathrm{Cl}-0.21-0.83, p<0.001)$. A poor ICC was demonstrated for RVSWI $\mathrm{ECHO}_{-1}(\mathrm{ICC}=0.45,95 \% \mathrm{Cl}-0.18-0.77$, $p<0.001)$. Agreement of absolute values for RVSWI $\mathrm{ECHO}-1_{1}$ was $-772 \pm 385(-50 \pm 20 \%) \mathrm{mmHg}^{*} \mathrm{~mL}^{*} \mathrm{~m}^{-2}, \mathrm{RVSWI}_{\mathrm{ECHO}-2}$ $-600 \pm 339(-41 \pm 20 \%) \mathrm{mmHg}^{*} \mathrm{~mL}^{*} \mathrm{~m}^{-2}$, RVSWI $\mathrm{ECHO}-342 \pm 286(5 \pm 25 \%) \mathrm{mmHg}^{*} \mathrm{~mL}^{*} \mathrm{~m}^{-2}$ and for RVSWI $\mathrm{ECHO}_{-4}$ $214 \pm 273(23 \pm 27 \%) \mathrm{mmHg}^{*} \mathrm{~mL}^{*} \mathrm{~m}^{-2}$.
\end{abstract}

Conclusion: The correlation with RVSWI $\mathrm{RHC}_{\mathrm{C}}$ was moderate to strong for all echocardiographic measures, whereas only RVSWI $\mathrm{ECHO}-3$ displayed high concordance of absolute values. The results, however, suggest that RVSWI $\mathrm{ECHO}-1_{1}$ or

\footnotetext{
${ }^{*}$ Correspondence: raluca.jumatate@med.lu.se

${ }^{1}$ Department of Clinical Sciences Lund, Cardiology, The

Echocardiographic Laboratory, The Section for Heart Failure and Valvular

Disease, VO. Heart and Lung Medicine, Skåne University Hospital, Lund

University, Skane University Hospital, Entrégatan 7, 22185 Lund, Sweden

Full list of author information is available at the end of the article
}

(c) The Author(s) 2021. Open Access This article is licensed under a Creative Commons Attribution 4.0 International License, which permits use, sharing, adaptation, distribution and reproduction in any medium or format, as long as you give appropriate credit to the original author(s) and the source, provide a link to the Creative Commons licence, and indicate if changes were made. The images or other third party material in this article are included in the article's Creative Commons licence, unless indicated otherwise in a credit line to the material. If material is not included in the article's Creative Commons licence and your intended use is not permitted by statutory regulation or exceeds the permitted use, you will need to obtain permission directly from the copyright holder. To view a copy of this licence, visit http://creativecommons.org/licenses/by/4.0/. The Creative Commons Public Domain Dedication waiver (http://creativeco mmons.org/publicdomain/zero/1.0/) applies to the data made available in this article, unless otherwise stated in a credit line to the data. 
$\mathrm{RVSWI}_{\mathrm{ECHO}-3}$ Could be the preferable echocardiographic methods. Prospective studies are warranted to evaluate the clinical utility of such measures in relation to treatment response, risk stratification and prognosis in patients with PAH.

Keywords: Echocardiography, Right ventricular stroke work index, Right heart catheterization

\section{Background}

In patients with pulmonary arterial hypertension (PAH), right ventricular (RV) function may deteriorate rapidly, constituting a negative prognostic factor for outcome [1, 2]. Non-invasive assessment of RV function is still challenging in patients with $\mathrm{PAH}$ and is mainly performed by transthoracic echocardiography. Compared to the left ventricle (LV), the morphology of the RV renders it more sensitive to changes in afterload (i.e. pressure overload) [3]. A simple surrogate measure of afterload by echocardiography is the calculation of systolic pulmonary arterial pressure (sPAP) by Bernoulli's equation using the maximum pressure gradient from an existing tricuspid regurgitation together with estimated $\mathrm{mRAP}_{\mathrm{ECHO}}[4,5]$. Clinically, RV afterload is generally defined as pulmonary vascular resistance (PVR) as measured by right heart catheterization (RHC). Using echocardiography, PVR can be assessed by the method suggested by Abbas et al. [6] or by using pulmonary acceleration time [4], however with poor accuracy. However, PVR does not quantify the compensation of RV work to changes in afterload [7]. With increasing PVR, the workload of the right ventricle will increase and vice versa. From a hemodynamical point of view, a more representative measure of the total RV workload is RV stroke work index (RVSWI), as it incorporates both stroke volume and pulmonary pressure, hence a determinant of RV failure [7]. Moreover, RVSWI $_{\mathrm{RHC}}$ also accounts for both the effect of preload, as it includes mean right atrial pressure (mRAP), as well as the effect of afterload, i.e. mean pulmonary pressure (mPAP). RVSWI being an invasive measure of RV function assessed by RHC, is calculated by the formula: $\mathrm{RVSWI}_{\mathrm{RHC}}=(\mathrm{mPAP}-\mathrm{mRAP}) \mathrm{x}$ stroke volume index (SVI).

In previous PAH studies, RVSWI $\mathrm{R}_{\mathrm{RHC}}$ has been shown to predict outcome in children $[8]$ and adults $[9,10]$. A proposed echocardiographic formula for RVSWI has been used in children with PAH. They calculated RVSWI by multiplying the tricuspid regurgitant maximum pressure gradient $\left(\mathrm{TR}_{\mathrm{maxPG}}\right)$ with $\mathrm{RV}$ stroke volume $(\mathrm{SV})$ using the stroke volume from the RV outflow tract (RVOT) [7]. However, indexation to body surface area (BSA) was not incorporated, and estimation of mRAP was not considered in this formula. Theoretically, RVSWI can been calculated by echocardiography in several different ways using either $\mathrm{TR}_{\operatorname{maxPG}}$ [7] or to mimic RHC, also incorporating mPAP. With echocardiography, mPAP can be estimated from the velocity integral of the TR doppler profile or from the early peak velocity of an existing pulmonary regurgitation with addition of $\mathrm{mRAP}_{\mathrm{ECHO}}$ [4]. RVSWI derived from echocardiography (RVSWI $\mathrm{ECHO}_{\text {) }}$ has, however, not been thoroughly compared to invasive measures in treatment naïve adults with PAH. Furthermore, the relevance of including BSA and mRAP in the echocardiographic equations are not elucidated. The aim of the present study was to evaluate the association and concordance between four different echocardiographically derived BSA-indexed methods of calculating RVSWI $_{\mathrm{ECHO}}$ to invasively calculated $\mathrm{RVSWI}_{\mathrm{RHC}}$, with and without incorporating echocardiographically estimated mRAP.

\section{Methods}

\section{Study population}

Initially, seventy consecutive adult patients with treatment naïve PAH examined from January $1^{\text {st }} 2012$ to December $31^{\text {th }} 2019$ at Skane University Hospital, Lund were retrospectively evaluated. In accordance with contemporary guidelines [11], the diagnosis of $\mathrm{PAH}$ were made by RHC in absence of other causes of pre- and postcapillary pulmonary hypertension (PH). Pre-capillary pulmonary hypertension was defined according to at the time existing guidelines $[11,12]$ as $\mathrm{mPAP} \geq 25 \mathrm{mmHg}$, pulmonary artery wedge pressure (PAWP) $<15 \mathrm{mmHg}$ and PVR $>3$ Wood Units (WU). The new suggested breakpoint of mPAP $>20 \mathrm{mmHg}$ at WSPH 2018 in Nice [13] was adopted in the latter phase of the study. Medical records were used for retrieving patient characteristics. Inclusion criteria were maximally 7 days between echocardiography and RHC, provided no clinical deterioration nor change in medical treatment between the exams. No patients with surgical corrected or unrepaired shunts were included in the study. None of the patients had more than mild pulmonary- or mitral regurgitation and no patient had more than trivial aortic regurgitation. Tricuspid regurgitation was present as mild (61\%) and moderate (39\%). Exclusion criteria were atrial fibrillation $(\mathrm{n}=2)$, poor echocardiographic image quality $(\mathrm{n}=4)$, pacemaker $(n=1)$, non-adequate tricuspid spectral doppler $(n=1)$, cardiac by-pass surgery $(n=1)$, myocardial infarction with decreased left ventricular systolic function $(\mathrm{n}=1)$, significant valvular disease (moderate aortic stenosis $(\mathrm{n}=2)$, mitral stenosis $(\mathrm{n}=1)$ and $>$ moderate tricuspid regurgitation $(\mathrm{n}=0))$ and previous treatment 
for PAH $(n=3)$. After exclusions, 54 patients remained available for inclusion in the study.

\section{Echocardiography}

All echocardiograms were obtained with an iE33 platform (Philips Healthcare, Eindhoven, NL) and a S5-1 transducer. Acquisition and assessment of echocardiographic measures were performed according to guidelines [14]. All echocardiographic images were stored digitally into an echocardiographic database (Philips IntelliSpace Cardiovascular, Philips Healthcare, Eindhoven, NL). Conventional RV function parameters as well as right ventricular free wall strain were assessed and analyzed as previously described by our research group according to guidelines $[14,15]$.

The pressure gradient between RV and RA was assessed by the tricuspid regurgitant velocity $\left(\mathrm{TR}_{\max \mathrm{PG}}\right)$ using the modified Bernoulli Eq. (5), Fig. 1. The tricuspid mean pressure gradient $\left(\mathrm{TR}_{\text {meanPG }}\right)$ was calculated by the velocity integral of the tricuspid regurgitant spectral doppler curve [4], Fig. 1. SVI $\mathrm{ECHO}_{\mathrm{H}}$ was calculated as: (left ventricular outflow tract (LVOT) area $\mathrm{x}$ velocity-time integral from LVOT)/BSA. For quantifying $\mathrm{mRAP}_{\mathrm{ECHO}}$, the diameter of vena cava inferior and its collapsibility were used according to guidelines [14].

Four different echocardiographic methods for calculation of RVSWI $\mathrm{ECHO}_{\text {were evaluated: }}$

1. $\mathrm{RVSWI}_{\mathrm{ECHO}-1}=\left(\mathrm{TR}_{\operatorname{maxPG}}\right) \times \mathrm{SVI}_{\mathrm{ECHO}}$,

2. $\mathrm{RVSWI}_{\mathrm{ECHO}-2}=\left(\mathrm{TR}_{\operatorname{maxPG}}-\mathrm{mRAP}_{\mathrm{ECHO}}\right) \times \mathrm{SVI}_{\mathrm{ECHO}}$,

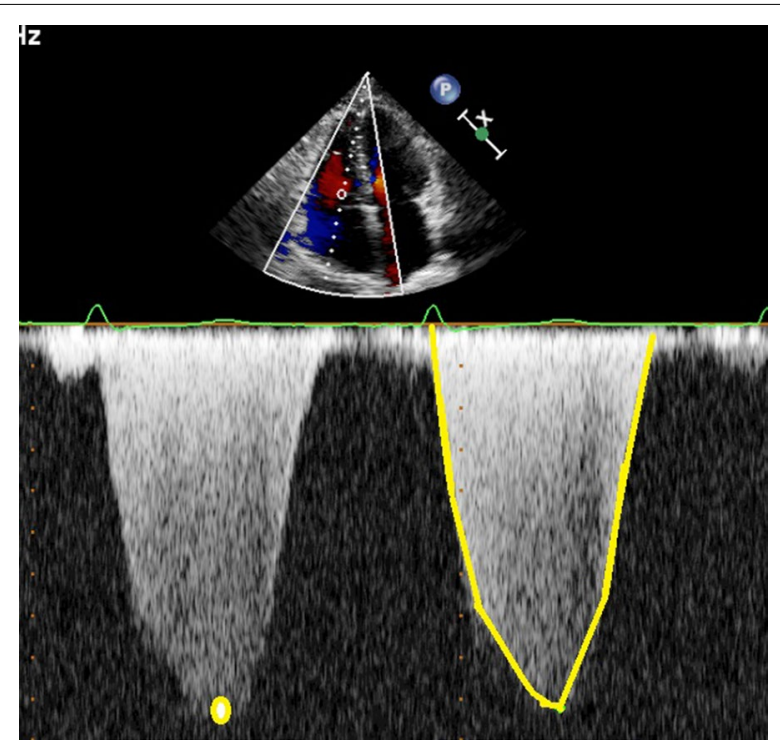

Fig. 1 Echocardiographic illustration of measurement of maximum (yellow dot) and mean (yellow delineation) pressure gradients from a tricuspid regurgitation
3. $\mathrm{RVSWI}_{\mathrm{ECHO}-3}=\mathrm{TR}_{\text {meanPG }} \times \mathrm{SVI}_{\mathrm{ECHO}}$

4. $\mathrm{RVSWI}_{\mathrm{ECHO}-4}=\left(\mathrm{TR}_{\text {meanPG }}-\mathrm{mRAP} \mathrm{ECHO}_{\mathrm{EO}}\right) \times \mathrm{SVI}_{\mathrm{ECHO}}$.

\section{Right heart catheterization}

The patients underwent RHC under local anesthesia in supine position at rest. An 8 French sheath was inserted using the Seldinger technique predominantly via the right internal jugular vein. A Swan-Ganz catheter was used for pulmonary arterial pressures measurements (sPAP, mPAP and diastolic PAP), together with mRAP and PAWP, recorded at free breathing over five heartbeats. Cardiac output (CO), (i.e. pulmonary blood flow in $\mathrm{ml} / \mathrm{min}$ ) was calculated by thermodilution in all patients. SV (ml/beat) was determined by dividing CO by heart rate (beats/min). SV was indexed to BSA to obtain SVI (stroke volume index). PVR was calculated using: (mPAP-PAWP)/CO. Systemic blood pressure was measured using an arm-cuff and sphygmomanometer. Mixed venous oxygen saturation was obtained for each patient. RVSWI $_{\text {RHC }}$ was calculated as: (mPAP - mRAP) x SVI.

\section{Statistical analysis}

Continuous data was expressed as mean \pm standard deviation (SD) or median with inter-quartile range [IQR], as appropriate. Normality was assessed visually from histograms and confirmed by Kolmogorov Smirnov test. Categorical data was expressed in absolute numbers and proportion (percentage). The association between the four different measured RVSWI $\mathrm{ECHO1-4}_{4}$ and the invasively measured RVSWI $\mathrm{RHC}_{\mathrm{C}}$ was evaluated using Pearson's and intraclass correlation coefficients (ICC). The degree of correlation between tests was classified as either weak $(\mathrm{r}<0.5)$, moderate $(0.5-0.7)$, strong $(0.7-0.9)$ or very strong (0.9-1.0) [16]. For calculating ICC, a two-way mixed model for absolute agreement between the measurements was used [17]. The $95 \%$ confidence interval (CI) of the ICC estimate was classified as either poor $(<0.5)$, moderate (0.5-0.75), good (0.75-0.9) and excellent reliability $(>0.9)$. Agreement of absolute measures from different modalities was computed as described by Bland and Altman [18]. Two-tailed P-values $<0.05$ were considered statistically significant. Analyses were performed by commercially available software (IBM, SPSS Statistics, version 25, Chicago, IL, USA).

\section{Ethical aspects}

The study complies with the Declaration of Helsinki and was approved by the regional department of the Swedish Ethical Review Authority (Dnr 2010/114, Dnr 2010/248 Dnr 2010/442). Written informed consent was given by the patients allowing analysis of all their clinical data including imaging, as granted in the ethical approval. 


\section{Results}

\section{Clinical characteristics}

Demographics and baseline characteristics of the included 54 patients ( 36 women, $65 \pm 13$ years) are shown in Table 1. Patients underwent assessment with echocardiography and RHC within a median time of 1 day [IQR 0-1 days] and were all diagnosed with PAH. The causes of PAH can be found in Table 1. No PAH disease specific treatment was given before the exams (i.e. all patients were $\mathrm{PAH}$ treatment naive). Most of the patients were in WHO-functional class II and class III (30\% and 61\%, respectively).

Baseline echocardiographic and RHC characteristics are shown in Table 2. All patients exhibited normal

Table 1 Baseline characteristics for demographic, clinical and laboratory parameters

\begin{tabular}{|c|c|}
\hline Number of patients ( $n$ ) & 54 \\
\hline Sex (women/men) & $36 / 18$ \\
\hline Age (years) & $65 \pm 13$ \\
\hline $\operatorname{BSA}\left(m^{2}\right)$ & $1.8 \pm 0.2$ \\
\hline \multicolumn{2}{|c|}{ Etiological subclasses of pulmonary arterial hypertension } \\
\hline Idiopathic PAH & $30(56)$ \\
\hline Heritable PAH & $3(5)$ \\
\hline PAH associated with CTD & $17(31)$ \\
\hline PAH associated with portal hypertension & $2(4)$ \\
\hline Drug and toxin induced PAH & $2(4)$ \\
\hline \multicolumn{2}{|l|}{ Laboratory parameters } \\
\hline NT-proBNP (ng/L) & $1698[375-3147]$ \\
\hline Hemoglobin (g/L) & $141 \pm 19$ \\
\hline Creatinine ( $\mu \mathrm{mol} / \mathrm{L})$ & $94 \pm 30$ \\
\hline \multicolumn{2}{|l|}{ Comorbidities } \\
\hline Diabetes & $15(28)$ \\
\hline Hypertension & $24(44)$ \\
\hline Coronary artery disease & $10(19)$ \\
\hline Previous stroke & $3(5)$ \\
\hline Thyroid disease & $14(26)$ \\
\hline \multicolumn{2}{|l|}{ Functional class, NYHA } \\
\hline I & $1(2)$ \\
\hline$\|$ & $16(30)$ \\
\hline III & $33(61)$ \\
\hline IV & $4(7)$ \\
\hline \multicolumn{2}{|l|}{ Medication } \\
\hline $\mathrm{O}_{2}$ & $12(22)$ \\
\hline Diuretics & $26(48)$ \\
\hline Calcium antagonists & $12(22)$ \\
\hline Anticoagulation & $7(13)$ \\
\hline
\end{tabular}

Data are expressed as mean $\pm S D$, median [inter-quartile range] or as number. Categorical data is2) expressed in absolute numbers and proportion (percentage). BSA (body surface area), CTD (connective tissue disease), NT-proBNP (brain natriuretic peptide), NYHA class (New York Heart Association) functional classification for heart failure
Table 2 Echocardiographic and right heart catheterization characteristics

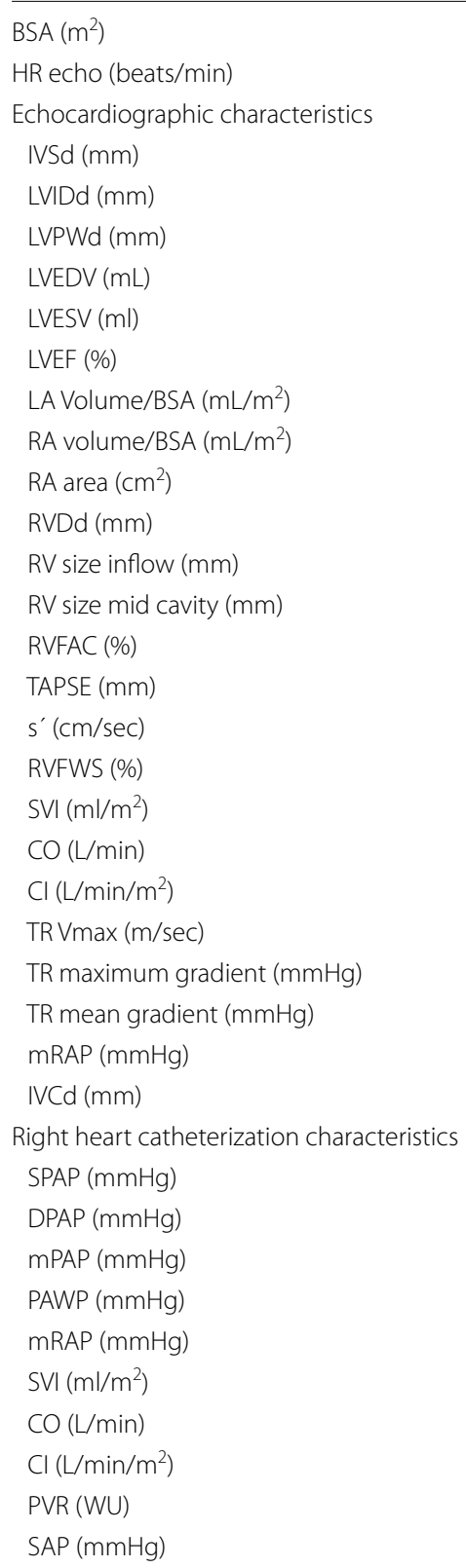

$1.8 \pm 0.2$

$83 \pm 15$

$10.3 \pm 0.2$

$40.9 \pm 7.5$

$9.3 \pm 2.1$

$57 \pm 23$

$23 \pm 14$

$61 \pm 10$

$23 \pm 11$

$43 \pm 20$

$22 \pm 7$

$36 \pm 6$

$48 \pm 10$

$37 \pm 9$

$27 \pm 12$

$17 \pm 5$

$10 \pm 2.9$

$-13.4 \pm 4.7$

$28.4 \pm 8.7$

$4.2 \pm 1.3$

$2.3 \pm 0.6$

$4.1 \pm 0.5$

$69 \pm 17$

$39 \pm 9$

8 [3-8]

$19 \pm 5$

$76 \pm 19$

$29 \pm 11$

$47 \pm 12$

7 [5-10]

$7 \pm 5$

$29.4 \pm 8.4$

$4.2 \pm 1.2$

$2.3 \pm 0.6$

$10.3 \pm 5.0$

$138 \pm 21$
Data are expressed as mean \pm SD or median [inter-quartile range]. BSA (body surface area), HR (heart rate), IVSd (intra ventricular septum diameter), LV (left ventricle), LVIDd (LV inner diastolic diameter), LVPWd (LV posterior wall diameter), LVEDV (LV end-diastolic volume), LVESV (LV end-systolic volume), LVEF (left ventricular ejection fraction), LA (left atrium), RA (right atrium), RV (right ventricle), RVDd (RV diastolic diameter in parasternal long axis view), RVFAC (RV fractional area change), TAPSE (tricuspid annular plane systolic excursion), $S^{\prime}$ (peak systolic velocity of the lateral tricuspid valve annulus), RVFWS (right ventricular free wall strain), SVI (stroke volume index), CO (cardiac output), Cl (cardiac index), TR (tricuspid regurgitation), TR Vmax (TR maximum velocity), mRAP (mean right atrial pressure), IVCd (inferior vena cava diameter), SPAP (systolic pulmonary arterial pressure), DPAP (diastolic pulmonary arterial pressure), mPAP (mean pulmonary arterial pressure), PAWP (pulmonary arterial wedge pressure), WU (Wood Units), PVR (pulmonary vascular resistance), SAP (systolic systemic arterial pressure) 
LV size and normal LV ejection fraction. The RV was dilated and had an impaired function measured by RV fractional area change and free wall strain compared to reference values [14]. The left atrium was within normal range whereas the right atrium was enlarged [14]. Median severity of the tricuspid regurgitation was mild. The pressures obtained by echocardiography were $69 \pm 17 \mathrm{mmHg}$ for $\mathrm{TR}_{\operatorname{maxPG}}, 39 \pm 9 \mathrm{mmHg}$ for $\mathrm{TR}_{\text {meanPG }}$

Table 3 Right ventricular stroke work index with right heart catheterization and echocardiography. Demonstrating differences in absolute values as well as biases (absolute and relative)

\begin{tabular}{|c|c|c|c|}
\hline $\begin{array}{l}\text { RVSWI (mmHg } \\
\left.x \mathrm{~mL} / \mathrm{m}^{2}\right)\end{array}$ & mean $\pm S D$ & Absolute bias & Relative bias (\%) \\
\hline$R V S W I_{\text {RHC }}$ & $1132 \pm 352$ & & \\
\hline RVSWI $_{\text {ECHO-1 }}$ & $1904 \pm 568^{* * *}$ & $-772 \pm 385$ & $-50 \pm 20$ \\
\hline $\mathrm{RVSWI}_{\mathrm{ECHO}-2}$ & $1732 \pm 531^{* * *}$ & $-600 \pm 339$ & $-41 \pm 20$ \\
\hline $\mathrm{RVSWI}_{\mathrm{ECHO}-3}$ & $1090 \pm 366^{\#}$ & $42 \pm 286$ & $5 \pm 25$ \\
\hline $\mathrm{RVSWI}_{\mathrm{ECHO}-4}$ & $918 \pm 336^{* * *}$ & $214 \pm 273$ & $23 \pm 27$ \\
\hline
\end{tabular}

Data are expressed as means \pm SD or as percentage. ${ }^{* * *} p<0.001,{ }^{\sharp} p=0.304$. RVSWI (right ventricular stroke work index), RHC (right heart catheterization), ECHO (echocardiography) and mean mRAP ECHO $_{\text {was }} 8$ [IQR 3-8] mmHg. By RHC, the patients exhibited mild to moderately raised mPAP (47 $\pm 12 \mathrm{mmHg}$ ), normal PAWP (7 [IQR 5-10] $\mathrm{mmHg}$ ), a moderate-severely elevated PVR ( $10 \pm 5 \mathrm{WU})$, a normal $\mathrm{CO}(4.2 \pm 1.2 \mathrm{~L} / \mathrm{min})$ and a normal to slightly elevated $\mathrm{mRAP}_{\mathrm{RHC}}$ of $7 \pm 5 \mathrm{mmHg}$.

Correlation between echocardiographic measures and RHC RVSWI derived from echocardiography and RHC are shown in Table 3. In comparison with $\mathrm{RVSWI}_{\mathrm{RHC}}$, RVSWI $_{\mathrm{ECHO}-1}$ and RVSWI $\mathrm{ECHO}-2_{2}$ were significantly higher $(p<0.001)$ whereas $\mathrm{RVSWI}_{\mathrm{ECHO}-4}$ were significantly lower in absolute values $(p<0.001)$. There was no difference for $\mathrm{RVSWI}_{\mathrm{ECHO}-3}(p=0.304)$. A strong correlation with RVSWI $\mathrm{RHC}_{\mathrm{RH}}$ was demonstrated for RVSWI $\mathrm{I}_{\mathrm{ECHO}-2}$ and $\mathrm{RVSWI}_{\mathrm{ECHO}-1}(\mathrm{r}=0.78$ and $\mathrm{r}=0.75, p<0.001)$ followed by a moderate correlation for $\mathrm{RVSWI}_{\mathrm{ECHO}-3}$ and RVSWI $_{\mathrm{ECHO}-4}(\mathrm{r}=0.66$ and $\mathrm{r}=0.69, p<0.001$ for all $)$ as illustrated in Fig. 2. A good agreement (ICC) was demonstrated for $\mathrm{RVSWI}_{\mathrm{ECHO}-3}$ (ICC $=0.80,95 \%$ CI $0.64-0.88$, $p<0.001)$, a moderate for $\mathrm{RVSWI} \mathrm{I}_{\mathrm{ECHO}-4}(\mathrm{ICC}=0.73,95 \%$ CI $0.27-0.87, p<0.001)$ and $\mathrm{RVSWI}_{\mathrm{ECHO}-2}(\mathrm{ICC}=0.55$, 95\% CI $-0.21-0.83, p<0.001)$. A poor ICC was demonstrated for RVSWI $\mathrm{ECHO}-1(\mathrm{ICC}=0.45,95 \% \mathrm{CI}-0.18-0.77$,

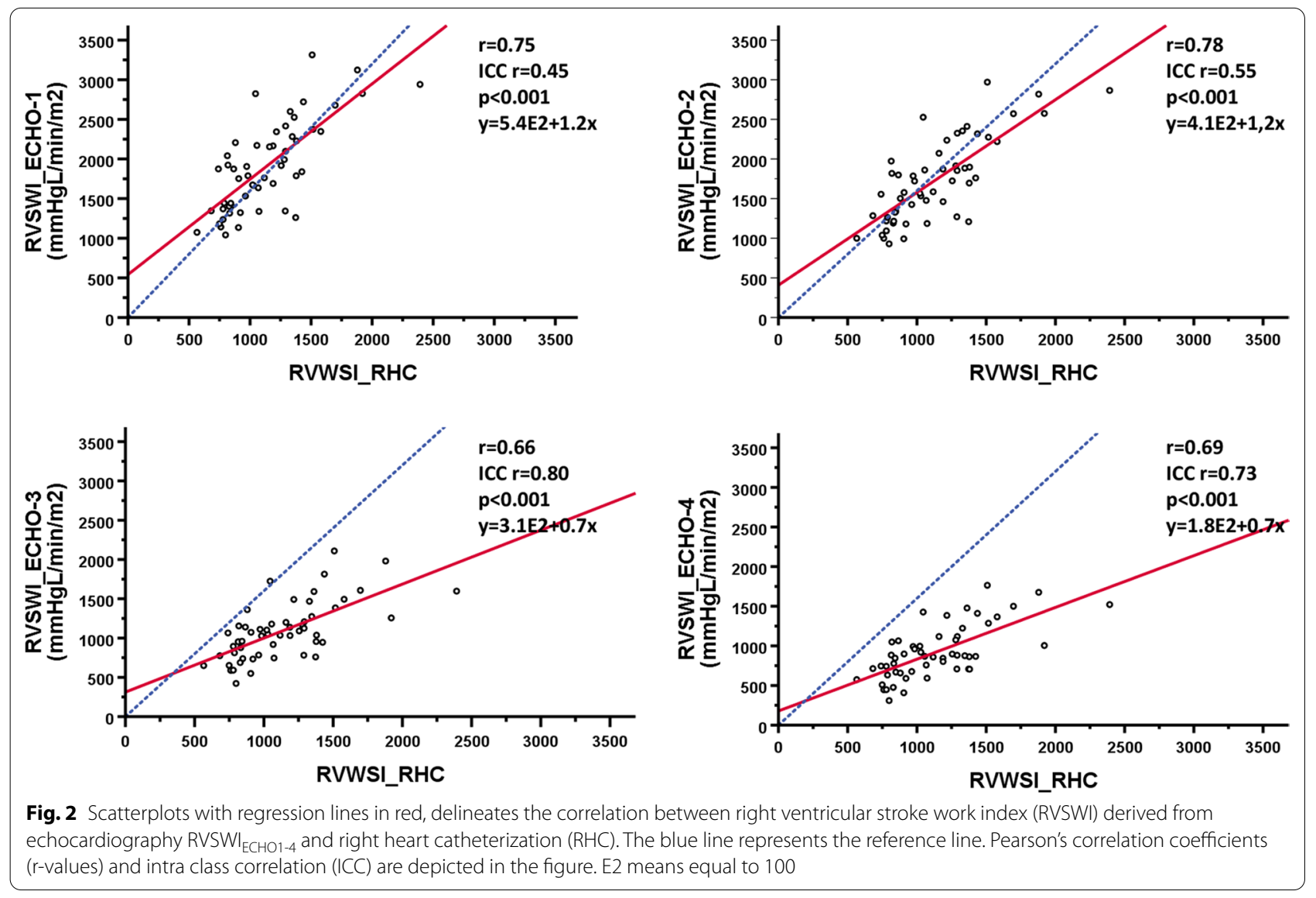


$p<0.001)$. The biases between the methods are illustrated in Fig. 3 and in Table 3, demonstrating the lowest bias for the calculated method RVSWI $\mathrm{ECHO}-3$.

\section{Discussion}

To our knowledge this is the first study comparing RVSWI $_{\mathrm{RHC}}$ with four different echocardiographic derived methods for calculation of RVSWI in treatment naïve adult patients with PAH. Our results show a small bias and no significant difference in absolute values between

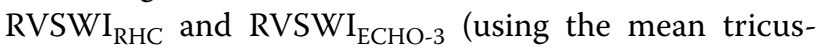
pid gradient and $\mathrm{SVI}_{\mathrm{ECHO}}$ ), albeit a moderate correlation between the methods. For the other three echocardiographic measurements, moderate to strong correlations with RVSWI $\mathrm{RHC}_{\mathrm{RHC}}$ were demonstrated, but poor concordance between values owing to larger biases.

\section{The concept of RVSWI}

RVSWI is the product of measured mRAP, mPAP and SV derived from RHC. Consequently, RVWSI incorporates elements of RV preload, afterload as well as contractile performance [8]. Previous studies have suggested that RVSWI could be used as a marker of clinical outcome since it reflects total RV workload $[19,20]$. In patients

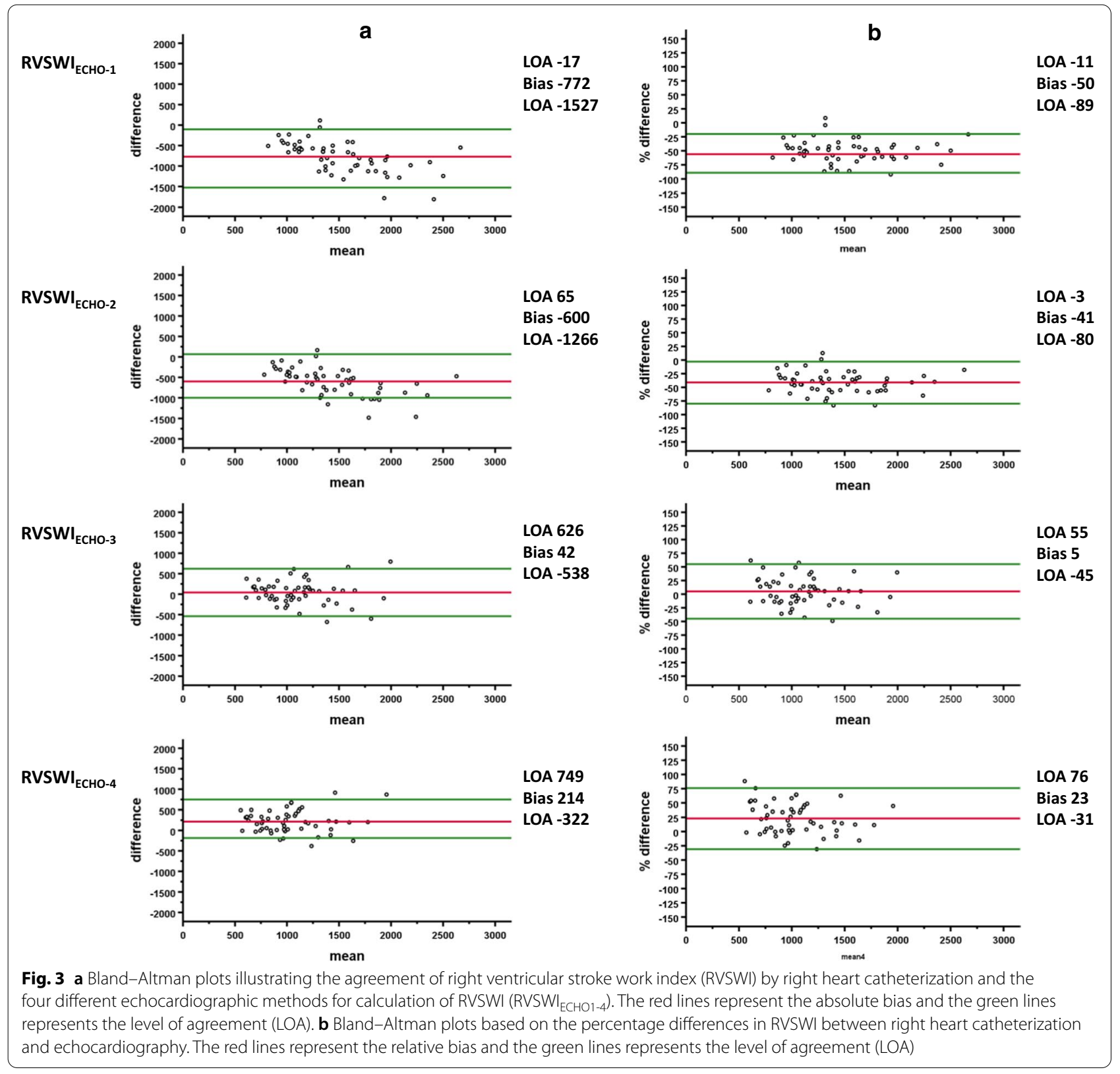


who have undergone lung transplantation, a higher RVSWI predicted worse outcomes [19]. RVSWI has also been used in patients with severe left ventricular heart failure eligible for left ventricular assist device to determine if the RV is sufficiently strong to meet the demands of the left ventricle and if a supplementary RV assistdevice is necessary [20]. In this setting a cut-off value for RVSWI $\leq 250 \mathrm{mmHg} \times \mathrm{mL} / \mathrm{m}^{2}$ is associated with a need of RV assist-device.

The role of RVSWI in patients with PAH is still an unexplored field. In children as well as in adults with PAH, RVSWI has, however, shown a prognostic value [8-10] but data are sparse.

The interpretation of RVSWI is however complicated and general cut off values for RVSWI has not been established. Initially, a high RVSWI indicates an increased workload of the RV, required as it strives to overcome an increased pulmonary vascular stiffness [21]. Clinically this is demonstrated in the early stages of PAH, whereas the RV can adapt physiologically with hypertrophy and increased contractility but without significant changes in size [22]. In the progress of the disease, RV dilatation occurs as a compensatory mechanism to maintain an adequate SV [22]. Theoretically, in this stage RVSWI reaches its plateau phase. Eventually, with a continuous rise in PVR, these compensatory mechanisms are inadequate resulting in progressive impairment in RV contractility and consequently a decrease in both SV and mPAP [22]. In this scenario RVSWI decreases. However, in clinical practice, specific drug therapy is initiated in the majority of patients diagnosed with PAH [11]. In this scenario, if the patient responds to treatment, RVSWI is affected due to a decrease in MPAP and an increase of SV. Nevertheless, since no reference values has been established, comparison of absolute RVSWI values between patients is challenging. Therefore, in clinical practice, the role of RVSWI may be best suited in follow-up assessments where the patients are their own reference. Even if the clinical use of RVSWI in this setting seems to be a promising tool it requires a RHC.

\section{Echocardiographic calculated RVSWI}

Finding new ways to noninvasively assess RV function in patients with PAH is of great importance. Although echocardiographic assessment of the RV has several limitations owing to its complex geometry, which challenges clinicians in daily practice, it is still the preferred imaging modality in daily routine. In this study we examined four different methods for non-invasive calculations of RVSWI using echocardiography-derived SV, pulmonary pressures and mRAP.

SV may be derived from either RVOT, or from LVOT. Unless there is intracardiac shunting or regurgitation of one or both semilunar valves present the SV may be considered equal. Since SV calculated from RVOT has several pitfalls, especially measuring the RVOT diameter [23], we used measurements from LVOT. In our study none of the patients had intra cardiac shunts or an aorticor pulmonary regurgitation. Consequently, SV calculated from LVOT was considered equal to SV calculated from RVOT in this study.

Using echocardiography, calculation of systolic and mean pulmonary arterial pressure can be estimated from the spectral doppler of an existing tricuspid regurgitation. In two of the methods (RVSWI $\mathrm{ECHO}-1_{1}$ and $\mathrm{RVSWI}_{\mathrm{ECHO}-2}$ ), the $\mathrm{TR}_{\operatorname{maxPG}}$ was used since it is an established non-invasive method for estimation of systolic pulmonary arterial pressures. The advantage using $\mathrm{TR}_{\operatorname{maxPG}}$ compared to the mean gradient is the accessibility since it is present in most PAH patients and easy to obtain. By echocardiography mPAP can be assessed in several ways [4]. In this study the velocity integral was used in two of the methods ( $\mathrm{RVSWI}_{\mathrm{ECHO}-3}$ and $\left.\mathrm{RVSWI}_{\mathrm{ECHO}-4}\right)$ since it has proven to exhibit a value closer to mPAP by RHC than the other methods [24, 25]. For the echocardiographic measurements using $\mathrm{TR}_{\operatorname{maxPG}}\left(\mathrm{RVSWI}_{\mathrm{ECHO}-1}\right.$ and $\left.\mathrm{RVSWI}_{\mathrm{ECHO}-2}\right)$ a strong correlation to RVSWI $\mathrm{RHC}_{\mathrm{RC}}$ were demonstrated, but poor agreement to the absolute values with large biases to be addressed. Incorporation of mRAP (RVSWI $\mathrm{ECHO}-2)$ did not change the results. This is in alignment with a study in children with PAH, where mRAP were not included, and a similar correlation was demonstrated [7].

For the echocardiographic measurement using $\mathrm{TR}_{\text {meanPG }}$ (RVSWI $\mathrm{ECHO}-3$ and RVSWI $\mathrm{ECHO}_{\mathrm{ECH}}$, respectively)

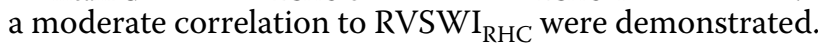
The method using only mPAP (RVSWI $\mathrm{ECHO}_{-3}$ ) showed no difference in absolute values compared to $\mathrm{RVSWI}_{\mathrm{RHC}}$. Therefore, incorporation of echocardiographic estimated mRAP using IVC had no incremental value in non-inva-

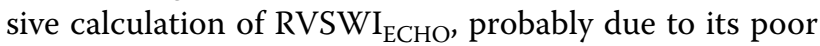
accuracy in the clinical settings [26]. In comparison to RHC, none of the echocardiographically derived methods could demonstrate both good correlation and high agreement in absolute values. The differences between invasively and echocardiographic derived RVSWI could also be explained by errors from both modalities.

By echocardiography, potential sources or error consist of inaccuracy in calculating SV as well as the pulmonary pressures. Concerning SV, measuring the diameter from an outflow tract has well known limitations. Calculations of LVOT-flow and TR-gradient are Doppler-derived. Thus, they both are angle dependent which can lead to underestimation. Moreover, overestimation must be avoided by ensuring that measurements are performed only on well-defined spectral curve. Another source of bias in measurements of pulmonary pressures between 
the methods is estimation of mRAP by echocardiography which consequently could lead to disagreement. Concerning RHC, thermodilution can overestimate SV, especially in low cardiac output states. Moreover, pressure calculations by RHC are dependent on correct calibration and could be affected by respiration and arrhythmias.

However, the results suggest that either RVSWI $\mathrm{ECHO}_{\mathrm{E}}$ could be the preferred method according to its level of correlation or RVSWI $\mathrm{ECHO}-3_{3}$ according to its better agreement with RHC. One major drawback of RVSWI is to identify if a decrease in RVSWI is due to treatment response (lower mPAP) or RV failure since both results in a decrease in TR pressure gradient. Additional clinical parameters, such as 6-min walk test, NT-proBNP, echocardiographic RV function parameters or changes in SVI, could be considered for differentiation.

\section{Clinical implications}

In our PAH-clinic, we routinely perform serial echocardiographic evaluations, right heart catheterizations and clinical assessments in combination with 6-min walk tests according to ESC:RRS risk stratification [11]. Even if conventional echocardiographic parameters (i.e. TAPSE, RVFAC and RVFWS) have an established role in the clinical assessment of RV function, they have not been implemented in the risk assessment algorithm in $\mathrm{PAH}$ [11]. In the clinical setting it is of great importance to early identify a failing RV in order to in a timely manner determine when the patient needs to be listed for lung transplantation. Consequently, an exploration to identify useful echocardiography-derived measurements besides RA area and the presence of pericardial effusion are warranted. RVSWI measured by echocardiography could be a new method for prognosis assessment in adult patients with $\mathrm{PAH}$ preferable for follow-up in selected cases where the patients are their own reference. However, it is highly unclear at present whether echocardiographically derived RVSWI have additive value in these patients. Certainly, more studies are needed to understand the clinical implication on how to interpret $\mathrm{RVSWI}_{\mathrm{ECHO}}$ and its role in management of these patients.

\section{Limitations}

There are some limitations to our study. The use of invasively measured RVSWI for estimation of prognosis in PAH patients is not fully explored, which makes the utility of echocardiographically RVSWI also unclear. Consequently, the results of this study should merely be described as a proof of concept study.

The number of patients is furthermore relatively small. However, PAH is a rare disease and it is therefore difficult to obtain large study cohorts. Echocardiography and RHC were not performed simultaneously. However, most patients had examinations the same day or the following day with no medical changes. Even though the delay was minimal, this could have influenced the result.

Systemic blood pressure was only obtained invasively and not in conjunction to the echocardiographic examination that could to some extent have affected the results.

A concern is that our study estimated $\mathrm{CO}$ from the LVOT considering it equal to CO from the RVOT. However, in the presence of a severe tricuspid regurgitation, the RV-workload could increase. Thus, RVSWI would be inaccurate. Our study population comprised patients with mainly mild tricuspid regurgitation and none with more than moderate TR. Moreover, SVI calculated by echocardiography and by RHC were similar. This is despite the fact that moderate or severe tricuspid regurgitation is associated with underestimation of cardiac output measured by thermodilution [27], further exacerbating any difference. We therefore conclude that this issue did not affect the present study, but feel that the validity of derived calculation will lose accuracy and validity in the presence of severe TR.

By echocardiography, CO derived from RVOT measurement is challenging in most patients and have well known limitations in clinical practice [28].

\section{Conclusion}

The correlation between RVSWI $\mathrm{RHC}_{\mathrm{C}}$ and all echocardiographic calculations of RWSVI was moderate to strong, while only $\mathrm{RVSWI}_{\mathrm{ECHO}-3}$ displayed high concordance of absolute values. Incorporation of echocardiographyestimated mRAP had no incremental value in non-invasive calculation of RVSWI. In this study we were unable to find any single method that showed both good correlation and high agreement in absolute values compared to RHC. However, the results suggest that either RVSWI $_{\mathrm{ECHO}-1}$ could be the preferred method according to its level of correlation or RVSWI $\mathrm{ECHO}-3$ according to its agreement to RHC. Future studies are needed to establish cut-off value for echocardiographically measured RVSWI and to evaluate the clinical utility of such measures in relation to $\mathrm{PAH}$ treatment response, risk stratification and prognosis.

\section{Abbreviations}

BSA: Body surface area; CO: Cardiac output; ECHO: Echocardiography; ICC: Intraclass correlation coefficients; LV: Left ventricle; LVOT: Left ventricular outflow tract; mPAP: Mean Pulmonary arterial pressure; mRAP: Mean right atrial pressure; PAH: Pulmonary arterial hypertension; PAP: Pulmonary arterial pressure; PH: Pulmonary hypertension; PVR: Pulmonary vascular resistance; RA: Right atrium; RHC: Right heart catheterization; RV: Right ventricle; RVOT: Right ventricular outflow tract; RVFAC: Right ventricular fractional area change; RVFWS: Right ventricular free wall strain; RVSWI: Right ventricular stroke work index; SV: Stroke volume; SVI: Stroke volume index; TAPSE: Tricuspid annular plane systolic excursion; $\mathrm{TR}_{\operatorname{maxPG}}$ : Tricuspid regurgitation maximum pressure gradient; $\mathrm{TR}_{\text {meanPG: }}$ Tricuspid mean pressure gradient. 


\begin{abstract}
Acknowledgements
We wish to acknowledge our appreciation of the support from the staff at the Echocardiographic Laboratory, The section for Heart Failure and Valvular Disease, VO Heart and Lung medicine, Skåne University Hospital and the staff at Lund University, Departments of Clinical Sciences Lund, Cardiology and Clinical Physiology, Lund, Sweden.
\end{abstract}

\section{Authors' contributions}

All authors (RJ, Al, GJS, AR, EO, JW, GR, CM, and AWE) contributed to the study conception and design of the work. Acquisition of echocardiographic images were performed by AWE and Al. Right heart catheterization was performed by GR. Analysis and interpretation of data was performed by RJ, AWE and CM. Proofing was done by JW. Revision has been performed by RJ, GR, Al, GJS, CM, $J W, E O$ and AWE. The first draft of the manuscript was written by RJ and AWE. All authors (RJ, Al, GJS, AR, EO, JW, GR, CM, and AWE) have approved the submitted version and the modified version of the manuscript. All authors ( $\mathrm{RJ}, \mathrm{Al}$, GJS, AR, EO, JW, GR, CM, and AWE) have agreed that the work is appropriately investigated, resolved and resolution documented in the literature. All authors read and approved the final manuscript.

\section{Funding}

Open access funding provided by Lund University. Raluca Jumatate was supported by research grants from the Swedish Society of Pulmonary Hypertension.

\section{Availability of data and materials}

The datasets generated and/or analysed during this study are not available for publications due to research subject confidentiality. They are available in a unidentified form from the corresponding author on reasonable request.

\section{Declarations}

\section{Ethics approval and consent to participate}

The study complies with the Declaration of Helsinki and was approved by the regional department of the Swedish Ethical Review Authority (Dnr 2010/114, Dnr 2010/248 Dnr 2010/442). Written informed consent was given by the patients allowing analysis of all their clinical data including imaging, as granted in the ethical approval.

\section{Consent to publish}

Not applicable.

\section{Competing interests}

No conflicts of interest.

\section{Author details}

${ }^{1}$ Department of Clinical Sciences Lund, Cardiology, The Echocardiographic Laboratory, The Section for Heart Failure and Valvular Disease, VO. Heart and Lung Medicine, Skåne University Hospital, Lund University, Skane University Hospital, Entrégatan 7, 22185 Lund, Sweden. ${ }^{2}$ Department of Clinical Sciences Lund, Clinical Physiology, Skane University Hospital, Lund University, Lund, Sweden. ${ }^{3}$ Liverpool Heart and Chest Hospital, Liverpool, UK.

Received: 1 October 2020 Accepted: 21 April 2021

Published online: 30 April 2021

\section{References}

1. Fine NM, Chen L, Bastiansen PM, Frantz RP, Pellikka PA, Oh JK, et al. Outcome prediction by quantitative right ventricular function assessment in 575 subjects evaluated for pulmonary hypertension. Circ Cardiovasc Imaging. 2013;6(5):711-21.

2. Simonneau G, Gatzoulis MA, Adatia I, Celermajer D, Denton C, Ghofrani A, et al. Updated clinical classification of pulmonary hypertension. J Am Coll Cardiol. 2013;62(25 Suppl):D34-41.

3. Haddad F, Couture P, Tousignant C, Denault AY. The right ventricle in cardiac surgery, a perioperative perspective: I. Anatomy, physiology, and assessment. Anesthesia Analgesia. 2009;108(2):407-21.
4. Rudski LG, Lai WW, Afilalo J, Hua L, Handschumacher MD, Chandrasekaran K, et al. Guidelines for the echocardiographic assessment of the right heart in adults: a report from the American Society of Echocardiography endorsed by the European Association of Echocardiography, a registered branch of the European Society of Cardiology, and the Canadian Society of Echocardiography. Journal of the American Society of Echocardiography : official publication of the American Society of Echocardiography. 2010;23(7):685-713; quiz 86-8.

5. Yock PG, Popp RL. Noninvasive estimation of right ventricular systolic pressure by Doppler ultrasound in patients with tricuspid regurgitation. Circulation. 1984;70(4):657-62.

6. Abbas AE, Franey LM, MarwickT, Maeder MT, Kaye DM, Vlahos AP, et al. Noninvasive assessment of pulmonary vascular resistance by Doppler echocardiography. J Am Soc Echocardiogr. 2013;26(10):1170-7.

7. Di Maria MV, Burkett DA, Younoszai AK, Landeck BF 2nd, Mertens L, Ivy $\mathrm{DD}$, et al. Echocardiographic estimation of right ventricular stroke work in children with pulmonary arterial hypertension: comparison with invasive measurements. J Am Soc Echocardiogr. 2015;28(11):1350-7.

8. Di Maria MV, Younoszai AK, Mertens L, Landeck BF 2nd, Ivy DD, Hunter $\mathrm{KS}$, et al. RV stroke work in children with pulmonary arterial hypertension: estimation based on invasive haemodynamic assessment and correlation with outcomes. Heart. 2014;100(17):1342-7.

9. Brittain EL, Pugh ME, Wheeler LA, Robbins IM, Loyd JE, Newman JH, et al. Shorter survival in familial versus idiopathic pulmonary arterial hypertension is associated with hemodynamic markers of impaired right ventricular function. Pulm Circ. 2013;3(3):589-98.

10. Clapham KR, Highland KB, Rao Y, Fares WH. Reduced RVSWI Is Associated with increased mortality in connective tissue disease associated pulmonary arterial hypertension. Frontiers in cardiovascular medicine. 2020;7(77).

11. Galie N, Humbert M, Vachiery JL, Gibbs S, Lang I, Torbicki A, et al. 2015 ESC/ERS Guidelines for the diagnosis and treatment of pulmonary hypertension: the joint task force for the diagnosis and treatment of pulmonary hypertension of the european society of cardiology (ESC) and the European Respiratory Society (ERS): Endorsed by: Association for European Paediatric and Congenital Cardiology (AEPC), International Society for Heart and Lung Transplantation (ISHLT). Eur Heart J. 2016;37(1):67-119.

12. Galie N, Corris PA, Frost A, Girgis RE, Granton J, Jing ZC, et al. Updated treatment algorithm of pulmonary arterial hypertension. J Am Coll Cardiol. 2013;62(25 Suppl):D60-72

13. Simonneau G, Montani D, Celermajer DS, Denton CP, Gatzoulis MA, Krowka M, et al. Haemodynamic definitions and updated clinical classification of pulmonary hypertension. Eur Respir J. 2019;53(1).

14. Lang RM, Badano LP, Mor-Avi V, Afilalo J, Armstrong A, Ernande L, et al. Recommendations for cardiac chamber quantification by echocardiography in adults: an update from the American Society of Echocardiography and the European Association of Cardiovascular Imaging. J Am Soc Echocardiogr. 2015;28(1):1-39.

15. Evaldsson AW, Lindholm A, Jumatate R, Ingvarsson A, Smith GJ, Waktare $J$, et al. Right ventricular function parameters in pulmonary hypertension: echocardiography vs cardiac magnetic resonance. BMC Cardiovasc Disord. 2020;20(1):259.

16. Mukaka MM. Statistics corner: a guide to appropriate use of correlation coefficient in medical research. Malawi Med J. 2012;24(3):69-71.

17. Koo TK, Li YM. A guideline of selecting and reporting intraclass correlation coefficients for reliability research. J Chiropr Med. 2016;15(2):155-63.

18. Bland JM, Altman DG. Statistical methods for assessing agreement between two methods of clinical measurement. Lancet (London, England). 1986;1 (8476):307-10.

19. Armstrong HF, Schulze PC, Kato TS, Bacchetta M, Thirapatarapong W, Bartels MN. Right ventricular stroke work index as a negative predictor of mortality and initial hospital stay after lung transplantation. J Heart Lung Transplant. 2013;32(6):603-8.

20. Fitzpatrick JR 3rd, Frederick JR, Hsu VM, Kozin ED, O'Hara ML, Howell E, et al. Risk score derived from pre-operative data analysis predicts the need for biventricular mechanical circulatory support. J Heart Lung Transplant. 2008;27(12):1286-92.

21. Stevens GR, Garcia-Alvarez A, Sahni S, Garcia MJ, Fuster V, Sanz J. RV dysfunction in pulmonary hypertension is independently related to pulmonary artery stiffness. JACC Cardiovasc Imaging. 2012;5(4):378-87. 
22. Vonk-Noordegraaf A, Haddad F, Chin KM, Forfia PR, Kawut SM, Lumens J, et al. Right heart adaptation to pulmonary arterial hypertension: physiology and pathobiology. J Am Coll Cardiol. 2013;62(25 Suppl):D22-33.

23. Yogeswaran V, Kanade R, Mejia C, Fatola A, Kothapalli S, Najam M, et al. Role of Doppler echocardiography for assessing right ventricular cardiac output in patients with atrial septal defect. Congenit Heart Dis. 2019;14(5):713-9.

24. Ristow B, Schiller NB. Stepping away from ritual right heart catheterization into the era of noninvasively measured pulmonary artery pressure. J Am Soc Echocardiogr. 2009;22(7):820-2.

25. Aduen JF, Castello R, Lozano MM, Hepler GN, Keller CA, Alvarez F, et al. An alternative echocardiographic method to estimate mean pulmonary artery pressure: diagnostic and clinical implications. J Am Soc Echocardiogr. 2009;22(7):814-9

26. Ostenfeld E, Werther-Evaldsson A, Engblom H, Ingvarsson A, Roijer A, Meurling C, et al. Right atrial volumes with 3D and 2D echocardiography are better than inferior vena cava for estimation of elevated right atrial pressure in pulmonary hypertension. Eur Heart J. 2014;35:884.

27. Balik M, Pachl J, Hendl J. Effect of the degree of tricuspid regurgitation on cardiac output measurements by thermodilution. Intensive Care Med. 2002;28(8):1117-21.

28. Groh GK, Levy PT, Holland MR, Murphy JJ, Sekarski TJ, Myers CL, et al. Doppler echocardiography inaccurately estimates right ventricular pressure in children with elevated right heart pressure. J Am Soc Echocardiogry. 2014;27(2):163-71.

\section{Publisher's Note}

Springer Nature remains neutral with regard to jurisdictional claims in published maps and institutional affiliations.
Ready to submit your research? Choose BMC and benefit from:

- fast, convenient online submission

- thorough peer review by experienced researchers in your field

- rapid publication on acceptance

- support for research data, including large and complex data types

- gold Open Access which fosters wider collaboration and increased citations

- maximum visibility for your research: over $100 \mathrm{M}$ website views per year

At BMC, research is always in progress.

Learn more biomedcentral.com/submissions 